\title{
Prevalence of HIV/AIDS in Nepal Army and its Dependants
}

\author{
Khatri $\mathbf{R}^{\mathbf{1}}$, Roka $\mathbf{K}^{\mathbf{1}}$ \\ 'Department of Medicine, Shree Birendra Hospital, Chhauni
}

\begin{abstract}
Introduction: The Asia Pacific Region is currently at the "tip of iceberg" phase of the HIV/AIDS epidemic after African countries causing irreparable economic damage and undermining national and regional security if left unattended. HIVIAIDS remains a serious national concern and potential for epidemic relapse is high ${ }^{1}$. Continued vigilance is important. Study of the Prevalence of HIVIAIDS in Nepal Army (NA) and its dependants is based on the data collected from various sources to highlight the importance of ongoing measures plus the need of effective programs against HIVIAIDS control.

Methods: This is a descriptive study and data are derived from February 1996 to March 2011 from the different sources. National Guideline for testing of HIV in Nepal, developed in 2003 was used for the diagnosis of the cases by blood tests in Birendra Hospital, Chhauni.

Results: Total of 116 cases was diagnosed HIV positive. Maximum number of HIV positive cases was diagnosed in the year 2010 as compared to other years since 1996 and for the year 2011 till the month of March. The positive cases diagnosed from army personnel in UN Mission and blood donation programs accounted for $0.02 \%$ and $0.09 \%$ respectively. And from the surgical patients in the army hospital, $0.18 \%$ cases were diagnosed positive. From the year 2006 to $2010,0.38 \%$ cases were diagnosed as positive among the voluntary counselling and testing (VCT) volunteers.

Conclusion: HIV is a threat to the army, behaviour change and prevention is the key and it needs to be adapted to the best. Intensive training, massive awareness programs and behavioural issues start at the recruit level and need to be reinforced prior and during deployment with regular monitoring of the soldiers activities.
\end{abstract}

Key words: AIDS, HIV, NA

\section{Introduction}

The mostadvanced stage of HIV infection is acquired immunodeficiency syndrome (AIDS) ${ }^{2}$. Heterosexual transmission is the commonest mode of HIV spread globally,4. The short term plan for AIDS prevention was implemented in $1988^{5}$. The first medium term plan for AIDS prevention and control was implemented in 1990-1992. Then in 1991, Sentinel Surveillance system was introduced. Simultaneously in 1992 counseling on HIVIAIDS was introduced. During the period of 1993-97 the second (multisectoral) medium term plan for AIDS prevention and control was implemented. In the year of 1993 safety of blood was introduced in policy. In 1994, first national AIDS and STD conference was held. Then in 1995 national policy on AIDS and STD prevention was issued. During the period of 1997-2001, strategic plan for HIVIAIDS prevention was made. Successively in 1998 second national AIDS and STD conference was held. In the period of 2002-2006, national HIVIAIDS strategic plan reviewed. From the time of 2003 till 2007 national HIVIAIDS operational plan were reviewed. From the time of 2006-2011, national HIV/AIDS strategic plan formulated and finally in 2006-2008 national HIV/ AIDS action plan (I) and in 2008-2011 national HIVIAIDS action plan (II) were endorsed. The national estimate of HIV/AIDS by the end of 2009 was $63,528^{6}$.

\section{Address for Correspondence:}

Name: Dr. Rishi Khatri

E-mail: khatririshi@ymail.com

Ph. №.: 9851009295 
Mobility, age group and opportunities for casual sex by military personnel are believed to make soldiers an especially high-risk group ${ }^{7}$. In accordance with the global efforts against HIVIAIDS Nepal Army Aids Control Office (NAACO) was established in the year 2003. Its major goals are to keep army community free from HIVIAIDS by regularly conducting HIV prevention program among NA personnel and their family members, to provide care and treatment to people living with HIVIAIDS. Its target population is 95,753 regular serving personnel; 350,000 family members and 400,000 of the retired personnel and their family.

NAACO has been conducting voluntary counselling and testing (VCT) services since December 1, 2006. It conducts regular counselling and voluntary testing for NA personnel (serving/retired) and their family members regarding HIVIAIDS. The regular HIV testing is done in peacekeepers participating in United Nations (Pre and Post Deployments), patients undergoing surgery in Birendra Hospital, Kathmandu and in various blood donation programmes conducted by Birendra hospital.

The objective of this study is to assess the prevalence of HIVIAIDS in Nepal Army and its dependants.

\section{Methods}

This is a descriptive study and data are derived from February 1996 to March 2011 from the following sources:-

1. NA personnel involved in the peace keeping missions.

2. As a routine procedure of NA personnel and their family members undergoing various surgeries in Birendra Hospital, Chhauni.

3. NA personnel involved in the blood donation programmes.

4. Personnel who were counselled and have volunteered for HIVIAIDS tests in the VCT program.

National Guideline for testing of HIV in Nepal, developed in 2003 was used for the diagnosis of the cases by blood tests using the standard enzyme linked immunosorbant assay (ELISA) method for detection of antibodies against HIV virus in Birendra Hospital, Chhauni.

\section{Results}

Total of 116 HIV positive cases were diagnosed in Nepal Army from February 1996 to March 2011.
Table1: HIV positive cases under different categories.

\begin{tabular}{|l|c|c|c|}
\hline Source & Total tests & Positive & Percentage \\
\hline UN Mission & 53,150 & 17 & 0.02 \\
\hline Blood Donation & 3,359 & 3 & 0.09 \\
\hline Surgical patients & 42,200 & 51 & 0.18 \\
\hline
\end{tabular}

The positive cases diagnosed from army personnel in UN Mission and blood donation programs accounted for $0.02 \%$ and $0.09 \%$ respectively. And from the surgical patients in the army hospital, $0.18 \%$ cases were diagnosed positive.

Table 2: HIV positive cases by VCT Programs.

\begin{tabular}{|l|c|c|c|c|}
\hline Year & Counselled & Volunteer & Positive & $\%$ \\
\hline $2006-2007$ & 1960 & 1150 & 7 & $0.61 \%$ \\
\hline $2007-2008$ & 4788 & 2298 & 9 & $0.39 \%$ \\
\hline $2008-2009$ & 4515 & 2308 & 8 & $0.35 \%$ \\
\hline $2009-2010$ & 8239 & 5084 & 18 & $0.33 \%$ \\
\hline Total & $\mathbf{1 9 5 0 2}$ & $\mathbf{1 0 8 4 0}$ & $\mathbf{4 2}$ & $\mathbf{0 . 3 8} \%$ \\
\hline
\end{tabular}

From the year 2006 to $2010,0.38 \%$ cases were diagnosed as positive among the VCT volunteers. Among the positive cases 34 were male while 8 of them were females. The highest number of positive cases (14) was from the age group 25-30 years. One case of three years old, born to HIV positive parents (vertical transmission) and another sixty years old retired person formed the extreme of ages among the positives.

Out of 116 HIV positive cases, 85 were males and 31 were females. 62 of the positive cases were detected in service army personnel while 1 case in serving policeman. 31 were the family members while 1 was a daughter; 10 people were already retired, 2 were civil people and 41 were the total dependants including 31 spouses. Almost every case regarded hetero-sexual contact as the possible route of the disease transmission except the single positive case of 3 years old boy who had contacted the disease from the infected parents. All of the positive males accepted to be the clients of female sex workers. All the positive female cases were the spouses of HIV infected husbands. The HIVIAIDS related symptoms were present among nine cases, 7 had Tuberculosis, 6 had some forms of sexually transmitted infections (STIs), 3 were asymptomatic, 18 had no specific medical reasons for HIV status evaluation. They volunteered after the VCT counselling. Among the positive cases 15 were clinically asymptomatic, 4 had advanced HIV infection, 7 had full blown AIDS and 17 of them were not assessed. Almost all of the positive cases were married, while only 2 were single. Among 
the married population, 13 of the spouses also tested positive for HIV, 6 tested negative. In the rest of the 20 cases, the HIV status remained unknown and the HIV status of their children could not be achieved. Majority of the positive cases belong to the age group of 26-30 yrs. Out of 116 positive cases, 14 have expired and 102 are living with Anti Retroviral Therapy.

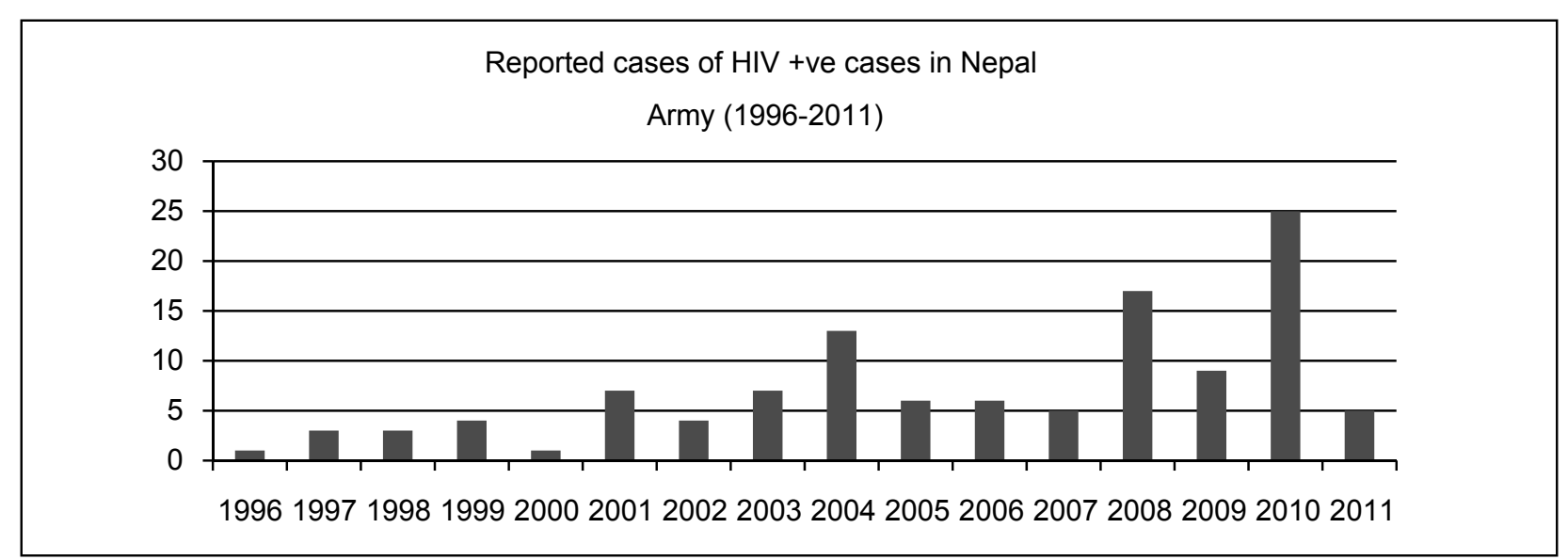

Fig 1: Year wise HIV positive cases

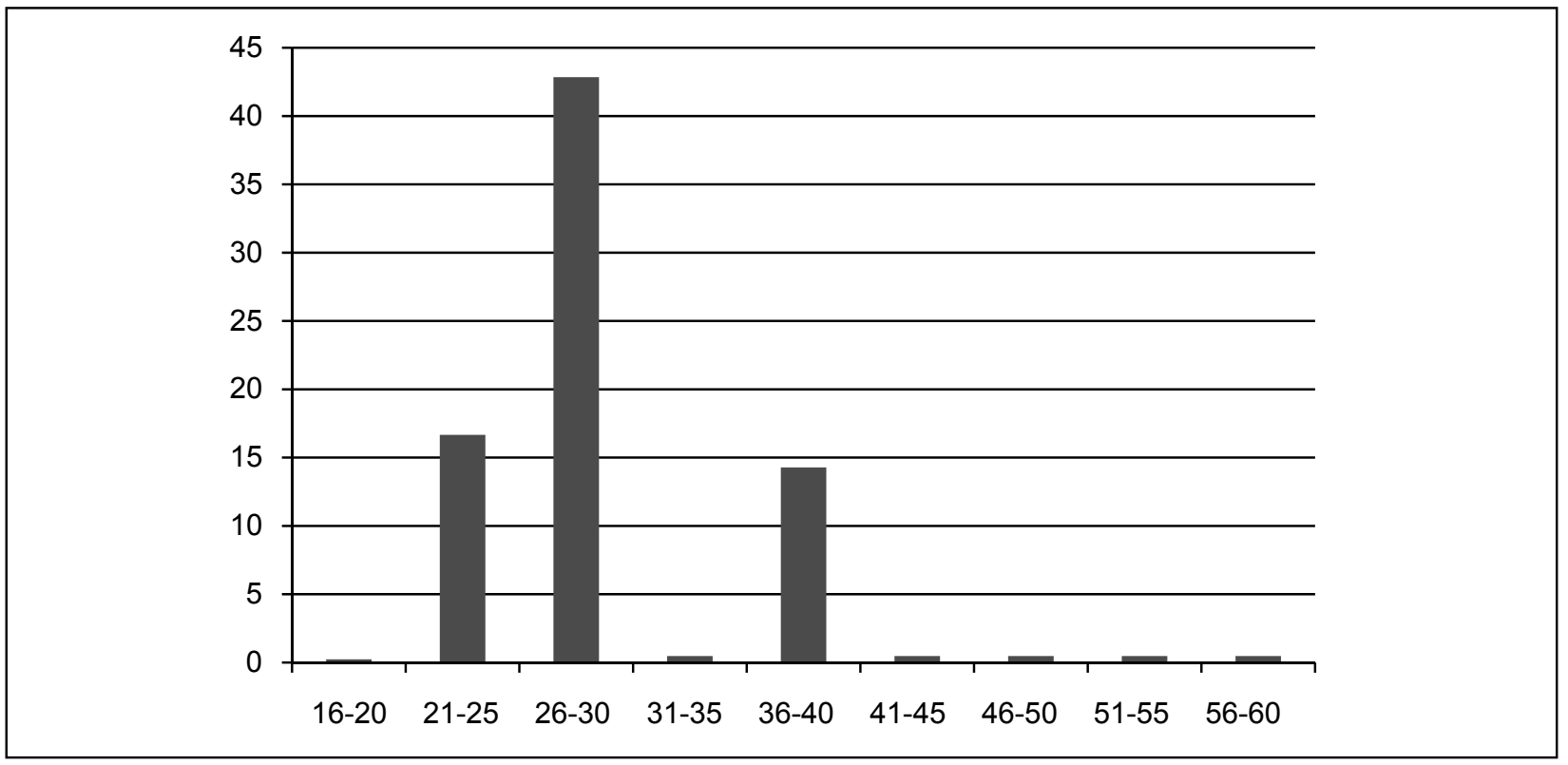

Fig 2: Percent of positive cases versus age group.

\section{Discussion}

From the various diagnostic measures, 116 cases were diagnosed in NA and its dependants. This might be the tip of iceberg of the actual prevalence. Figures for HIV infection rates in army are difficult to pin down - they either don't exist or governments cite concerns about national security and do not make them public. According to UNAIDS, "During peacetime, STIs rates among armed forces are generally 2 to 5 times higher than in comparable civilian populations; in times of conflicts, they can be more than 50 times higher." These figures are partly based on an international survey in the early 1990s, which found alarming HIV prevalence rates in some African militaries, but researchers have suggested that they do not reflect the current reality ${ }^{9}$. Studies in the USA, the UK, and France show that soldiers from these countries have a much higher risk of HIV infection than equivalent age/sex groups in the civilian population. In 1996, the Russian military forces were mainly being infected through sexual contact. From 1996 to 2001, needle sharing was the main route for infection. Since 2001 , both methods have had an approximately equal share among military personnel. For instance, in 2002, 
sexual contact was the listed mode of transmission in $51 \%$ of HIV cases and injection drug use with shared needles accounted for $45 \%$ of cases.

NA has been participating in United Nations Peace Keeping Operations for a long period. It has contributed 69,854 soldiers in 34 Peace Keeping Missions ${ }^{10}$. These deployments come along with the risk of spread of HIV from the UNPKs to host country and vice versa. In addition, some of the peace keeping missions are in the countries where the HIV is highly prevalent. Peacekeepers tend to have significantly more disposable income than local populations and the low-intensity nature of their operations means they often have time on their hands, and may become drivers of the local sex market. The culturally diverse makeup of peacekeeping missions and the regular rotation of personnel present challenges to awareness activities. Similar results were observed in Dutch navy and marines personnel on peacekeeping duty in Cambodia, stating that $45 \%$ of them had sexual contact with sex workers or other members of the local population during a five-month tour. Often condoms are not used consistently. A total of 53,150 cases have been tested so far, 17 cases found to be positive cases (postdeployment), nil (pre-deployment) and $4.7 \%$ of the NA peacekeepers confirmed of having sex with female sex workers (FSW) during the mission. Among the positive cases, HIV was prevalent in non-officer ranks probably due to the lack of sound knowledge regarding the disease process, transmission and progression. Majority of the positive cases are from the age group of 26-30 years.

After establishment of NA AIDS Control Office in 2003, the HIV testing is mandatory both pre and post deployment along with awareness programs. In 2005, Knowledge Attitude Behaviour and Practice Survey in NA were done and finally in 2007 NA HIVIAIDS policy was developed and implemented. The VCT program was launched in 2007. Along with the global campaigns against HIVIAIDS, NA has tried to keep it as free as possible from this global pandemic. Various programs as listed above has been brought up with the goals of keeping army community free of HIVIAIDS, conducting HIV prevention programs among NA personnel and family members, providing care and treatment to people living with HIVIAIDS (PLWHA), preventing spread of HIV in United Nations Peace Keeping Operations (UNPKO) and to enhance the national HIV prevention programs.

The United Nations Department of Peacekeeping Operations (UNDPKO) has adopted a number of HIV/ AIDS policies. Soldiers are not required to undergo HIV testing before deployment, but a medical exam excludes individuals displaying active symptoms of infection. All peacekeeping missions have either an HIVIAIDS policy adviser or, for smaller missions, an AIDS focal point responsible for developing awareness and prevention programmes. UNAIDS has developed an HIVIAIDS awareness card, available in 15 languages, which it distributes to all peacekeeping personnel. DPKO also ensures the availability of condoms and post-exposure prophylaxis (PEP) kits in case of needle-stick injury or rape.

The Royal Thai army since 1996 has strategies to prevent infection, identify infected personnel and supportive measures, and treatment. The Thai army also identified the need for multi-sectoral, domestic, and international collaboration. This was seen in agency cooperation with the Civil Military Alliance, international cooperation, UNICEF missions in China, and the UNDP in Cambodia. The UNDP in Cambodia assisted the Ministry of National Defence to devise an HIV plan in $1998^{11}$.

The U.S. Army-Wide HIVIAIDS Survey was administered anonymously in a two-stage random probability design to active duty Army personnel at 17 installations in the U.S. and Europe. Surveys collected $(\mathrm{N}=18,125)$ represented $74.2 \%$ of the assigned unit strength, and $95 \%$ of individuals present for duty at the time of administration. Analyses reported here were conducted on 18,055 surveys with complete information. Preliminary analyses on the unweighted data indicated the prevalence of risk-relevant behaviours hypothesized to be related to HIV exposure potential in the following domains: $14.5 \%$ reported at least one STD over the past 2 years; $37.5 \%$ had a least one partner whose HIV status was unknown and $7.4 \%$ had 5 or more of such partners over the past year; $11.3 \%$ reported at least one incident of intercourse-related (and menstruation unrelated) bleeding over the past year; $13 \%$ reported at least one incident of a sexual binge; $7.6 \%$ reported 10 or more sex partners during the past 12 months; $16.3 \%$ reported looking for new sexual partners in "risky" places (e.g., brothels, strip joints, on the street); $26 \%$ had sex with one or more people who lived in U.S. cities with high AIDS prevalence; $7.7 \%$ had sex with one or more persons who lived in countries with high AIDS prevalence. The following frequencies of sex with one or more "risky" partners over the past year were reported: "one night stands" $34 \%$; prostitutes $6 \%$, and "anonymous" partners $7 \%$. Of those reporting sex with these types of partners, $40 \%$ reported never using condoms with "one night 
stands," 25\% never used condoms with prostitutes, and $24 \%$ never used condoms with "anonymous" partners. Additional analyses will focus on psychosocial, demographic and situational factors associated with exposure risk behaviours ${ }^{12}$.

Whether or not military personnel transmit the virus to the civilian population, peacekeepers themselves are at risk. When Indian soldiers returned from peacekeeping duties in Cambodia in the 1990s, the Times of India alleged that 45 of them had contracted HIV. Nigerian troops on peacekeeping missions must test HIV-negative before they are deployed and are also tested on return. One study showed that $7 \%$ of returning peacekeepers had contracted HIV after one year, 10\% after 2 years and $15 \%$ after 3 years. While some may have contracted the virus while on home leave, the reality is that during peacekeeping missions there is a much higher probability of contracting HIV than of being killed in action. The extent to which peacekeepers spread HIV is uncertain. In 1992, when peacekeepers arrived in Cambodia, the country had no recorded case of HIVIAIDS and little or no commercial sex industry. Within 10 years, prostitution was widespread and Cambodia had the highest incidence of HIV per head of population in Asia. While some attribute the epidemic to peacekeepers, others argue that poverty and the rapid social change ${ }^{13}$.

Estimates during the late 1990s for Africa include $40-60 \%$ of Angolan soldiers (2.8\% of adult population), $10-25 \%$ in Congo (Brazzaville) $(6.4 \%$ of adult population), $4.6 \% 4$ in Eritrea (2.8\% of adult population), $15-30 \%$ in Tanzania (8.1\% of adult population) and $50 \%$ in Zimbabwe (25\% of adult population). In Cambodia in $1999,12-17 \%$ of the armed forces were estimated to be HIV positive, compared with $3.7 \%$ of the general population. In some countries, however, rates of HIV infection in the military remain low or have begun to fall, largely as the result of effective prevention programmes. The effective prevention campaigns in some countries like Morocco, Ethiopia and Thailand have shown good results. Morocco has an HIV infection rate of 3 in 10,000 in the adult population and only 2 in 100,000 in the army. Following a prevention campaign aimed at military personnel, the incidence of other STIs in its armed forces fell from a peak of over 5,000 cases a year in 1987 to 3,000 by 1996 . In Ethiopia, an infection rate of $5 \%$ in the armed forces, $2 \%$ lower than in the general population, is attributed to aggressive condom marketing techniques ${ }^{19}$. In Thailand, where the government aimed a massive "100\% condom" campaign at the whole country, HIV infection among soldiers dropped from
$12 \%$ in 1993 to under $3 \%$ in 1998 . Soldiers' visits to sex workers dropped from 80 to $38 \%$ in the same period, while fewer men reported having sex with a sex worker before joining the army (57\% in $1991 ; 8 \%$ in 1998$)^{14}$.

\section{Conclusion}

HIVIAIDS is a global and regional security issue that impacts the stability of the defense environment. Widespread HIV infection in the ranks threatens the ability of the Nepal army to respond to external threat or fulfil its other functions. Illness results in a loss of skills in all the ranks and loss of institutional memory which may contribute to a decline in military performance and breakdown in discipline and reduction in the pool of potential replacements with high focuses of HIV on national security. The Army HIV programmes are more effective if there is close collaboration with civilian health authorities. Probably the single most important factor leading to high rates of HIV in army is the posting of personnel far from their accustomed communities and families for varying periods of time and deputing them in African countries as UN peacekeepers where the prevalence of HIVIAIDS is already greater than in other countries. As well as freeing them from traditional social controls, it removes them from contact with spouses or regular sexual partners and thereby encourages growth of sex industries in the areas where they are posted. HIV is a threat to the army, at home, and to those in post conflict peacekeeping and humanitarian relief. Behaviour change and prevention is the key and it needs to be adapted to the best. Intensive training, massive awareness programs and behavioural issues start at the recruit level and need to be reinforced prior and during deployment with regular monitoring of the soldiers activities.

\section{References}

1. Kumar, Abbas, Fausto. Diseases of immunity. Text book of Pathologic Basis of Disease. $7^{\text {th }}$ edition; 2009: 245-255.

2. HIVIAIDS: Health Topics. World Health Organisation (WHO), [cited on 2011, March 29]. Available from: http://www.who.int/topics/hiv_aids/en/

3. Gottlieb MS. Pneumocystis pneumonia--Los Angeles. 1981. Am J PublONic Health 96 (6): 980-1; discussion 982-3. PMID 16714472. PMC 1470612.

4. Gottlieb MS, MD, HM Schanker, MD, PT Fan, MD, A Saxon, MD, JD Weisman, DO, Div of Clinical Immunology-Allergy; Dept of Medicine, UCLA 
School of Medicine; I Pozalski, MD, Cedars-Mt. Siani Hospital, Los Angeles; Field services Div, Epidemiology Program Office, CDC. [cited on 2011, March 29] Available from: http://www.cdc. $\mathrm{gov} / \mathrm{mmwr} /$ preview/mmwrhtml/june_5.htm

5. HIVIAIDS Health Profile. US AIDS.[ cited on 2011, March] 29. Available from: http://www.usaid. gov/our_work/global_health/aids/Countries/asia/ nepal_profile.pdf

6. National Centre for AIDS and STD Control (NCASC) [cited on 2011, March 29]. Available from: http:// www.ncasc.gov.np

7. HIVIAIDS and the military. Plus News. Project Phisida [cited on 2011, March 29] Available from: http://www.phisida.org.za/

8. Col. Dr. K. Rana. Voluntary HIV counselling and Testing in Nepal Army : implications for HIV prevention. APMMC XX, Jakarta, 3-7 $7^{\text {th }}$ May, 2010. [cited on 2011, March 29]. Available from: http:// www.apmmc.org/2010presentations/Thursday/ Breakout4_Sumatra/RANA.pdf
9. Whiteside A, Waal De A, Gebre T.AIDS, Security and the Military in Africa: a Sober Appraisal. African Affairs, January 2006.

10. Col. Dr. K. Rana. AIDS Prevention in Nepal Army Issues and Challenges, First Health Delivery Management Conference, Phitsanulok. [Cited on 2011, March 29].Available from: http://www.health. nu.ac.th/hdm2009/oral/15KP2_Rana.pdf

11. HIV /AIDS and Peacekeeping: Roxanne Bazergan. Asia Pacific Military Medicine Conference XIII. HIVI AIDS Report, May 12-16,2003.

12. HIV exposure with relevant behaviors in the US Army. Temoshok L. Blake SM, Rundell J R, Sharpes ES: International Conference on AIDS. 1992 July 19-24.

13. Combat AIDS: HIV and the World's Armed Forces. Health Link World Wide 2002.

14. The Gazette Online, Johns Hopkins University, April 1, 2002, www.jhu.edu/ gazette/2002/01apr02/ 01condom.html.

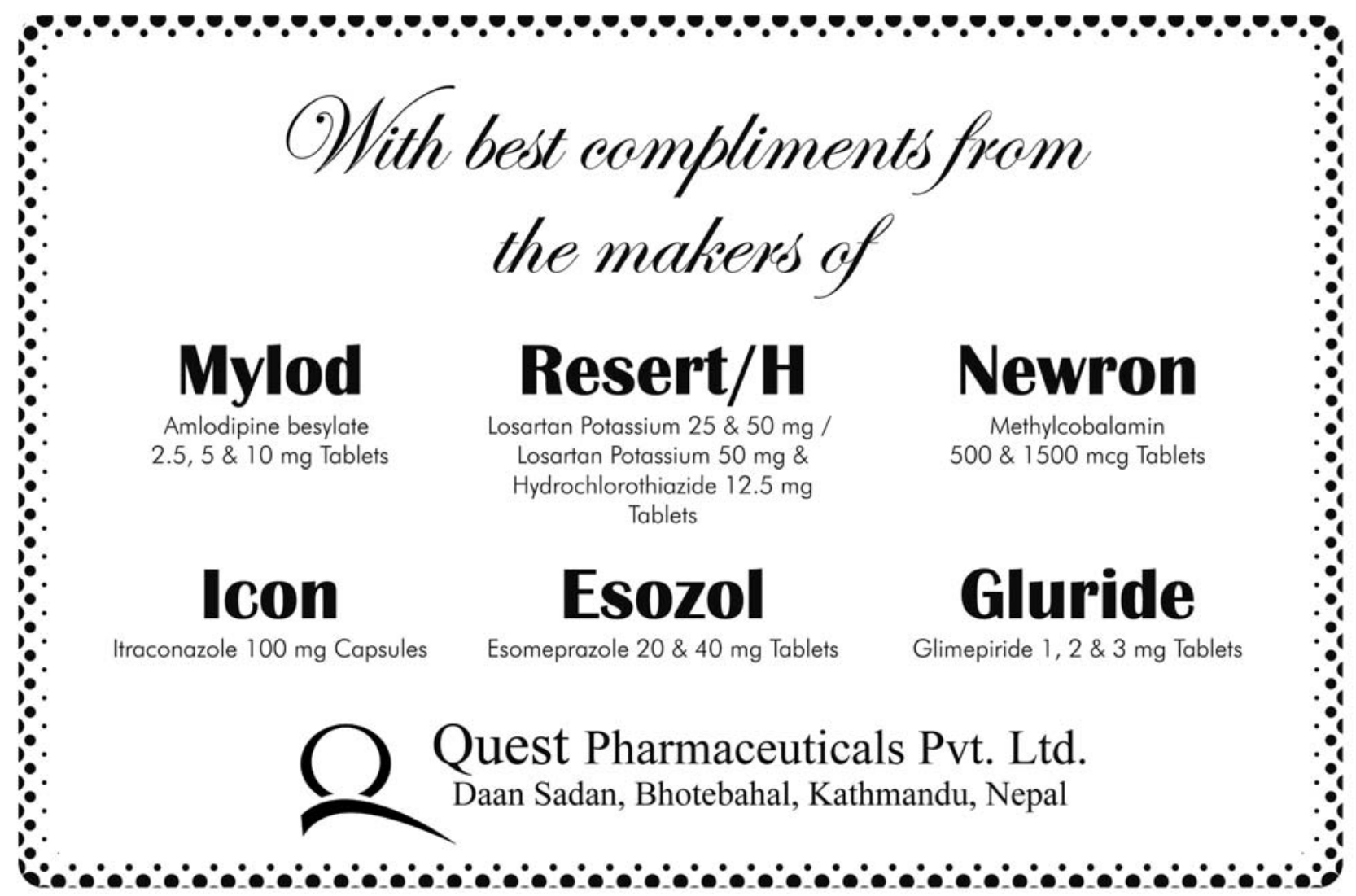

